\title{
Understanding Participation in SSI
}

Kathleen McGarry and Robert F. Schoeni

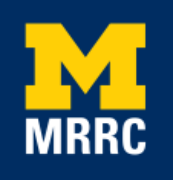

Project \#: UM14-08 


\title{
Understanding Participation in SSI
}

\author{
Kathleen McGarry \\ University of California, Los Angeles and NBER \\ Robert F. Schoeni \\ University of Michigan \\ January 2015
Michigan Retirement Research Center
University of Michigan
P.O. Box 1248
Ann Arbor, MI 48104
www.mrrc.isr.umich.edu
(734) 615-0422

\section{Acknowledgements}

This work was supported by a grant from the Social Security Administration through the Michigan Retirement Research Center (Grant \# 2 RRC08098401-06-00). The findings and conclusions expressed are solely those of the author and do not represent the views of the Social Security Administration, any agency of the Federal government, or the Michigan Retirement Research Center.

\section{Regents of the University of Michigan}

Michael J. Behm, Grand Blanc; Mark J. Bernstein , Ann Arbor; Laurence B. Deitch, Bloomfield Hills; Shauna Ryder Diggs, Grosse Pointe; Denise Ilitch, Bingham Farms; Andrea Fischer Newman, Ann Arbor; Andrew C. Richner, Grosse Pointe Park; Katherine E. White, Ann Arbor; Mark S. Schlissel, ex officio 


\title{
Understanding Participation in SSI
}

\begin{abstract}
The Supplemental Security Income program (SSI) provides a guaranteed income for the elderly. As such it can serve to mitigate any deleterious effects of reductions in Social Security benefits that might result from any Social Security reform. However, participation in SSI among qualified individuals has proven to be low. We show that this low participation rate, just over $50 \%$, observed at the program's inception has continued to today with little if any change. We also find that transfers from children are far larger among eligible non-participants suggesting that family assistance may offset the need for public assistance.
\end{abstract}

\section{Citation}

McGarry, Kathleen, and Robert F. Schoeni. 2015. "Understanding Participation in SSI.” University of Michigan Retirement Research Center (MRRC) Working Paper, WP 2015-319. Ann Arbor, MI. http://www.mrrc.isr.umich.edu/publications/papers/pdf/wp319.pdf 
The increasing financial pressure on the Social Security program, strongly suggests that important changes will be implemented in the not too distant future. Numerous ideas for “saving” Social Security have been put forth. Discussions of potential changes frequently include increases in the normal retirement age and changes to the Consumer Price Index — both of which will reduce benefits. These benefit reductions are likely to have significant implications for the wellbeing of low-income elderly who depend heavily on Social Security and who may have the greatest difficulty in working longer and managing with a reduced CPI adjustment.

The primary public support program for low-income elderly is the Supplemental Security Income Program (SSI). SSI provides a guaranteed income for the elderly, blind, and disabled. As such it provides an important backstop against any potentially deleterious effects of changes in Social Security and ought to be included in any study of Social Security reforms. The SSI program is based on the relatively simple concept of providing a guaranteed-minimum income for all those ages 65 or older and thus provides a ready mechanism to offset reductions in Social Security for the poorest Americans. However, despite the goals of the program, enrollment is not automatic at age 65 and many of the elderly who are eligible for benefits from SSI are not participating. Numerous studies have consistently found participation rates at approximately 50 to 60 percent (Menefee et al., 1981; Warlick, 1982; McGarry, 1996), rates that are evident even 20 years after the program's inception (McGarry, 2002). Understanding this low level of participation is likely to be increasingly important if Social Security benefits fall in real terms and more individuals face income below the SSI guarantees.

Explanations for the relatively low levels of participation have highlighted a lack of information about the program, the difficulty of the application process, and the stigma associated with accepting welfare benefits (McGarry, 1996). 
In this project we re-examine participation in SSI, drawing on the rich data in the Health and Retirement Study (HRS). We examine participation over an extended period of time, during which there were both significant economic and social changes such that the importance of many of these hypothesized barriers to participation may have changed. We also propose a new explanation for the low rates of participation, that being the potential for support from children, and assess whether family transfers provide a supplement or alternative to public assistance.

\section{Background}

Title 1 of the Social Security Act in 1935 provided federal funding to state-run

Old Age Assistance programs, helping to expand these programs nationwide. There were large cross-state differences in the level of benefits and strict rules on relative responsibility, state residency, and lien laws. In 1972 President Richard Nixon signed the Supplemental Security Income program into law, and it began paying benefits in 1974. This new federal program replaced the state-run assistance Old Age Assistance programs, as well as state Aid to the Blind programs and Aid to the Permanently and Totally Disabled. The federal SSI program is administered by the Social Security Administration and guarantees a minimum monthly income; states are free to supplement these benefits and provide a higher income floor. When first enacted, federal guarantees were \$140 per month for single persons and \$210 for married couples, and have been increased over time to adjust for inflation. ${ }^{1}$ In 2011 the guarantees were $\$ 698$ for single elderly individuals and $\$ 1,048$ for couples and all but six states (and the District of Columbia) provided some supplementation. ${ }^{2}$

\footnotetext{
${ }^{1}$ See McGarry (2014) for a short history of the program and Trout and Mattson (1984) for a more detailed analysis of the initial 10 years of the program.

${ }^{2}$ State supplemental programs are also administered by the Social Security Administration in most cases, although states may choose to administer their own program.
} 
The amount to which an individual or couple is entitled is determined by subtracting "countable income" from the specific guaranteed amount. Countable income is defined as total income less a series of disregards, primarily, the first \$20 of unearned income (typically Social Security), the first $\$ 65$ of earned income and one-half of earned income above $\$ 65$ (rare for the elderly). In addition to the income requirements, SSI includes an asset test. To be eligible for benefits, individuals must have assets below $\$ 2,000$ and couples below $\$ 3,000$. Again there are several exclusions in determining the value of assets including life insurance, burial plots, a car valued at less than $\$ 4,500$, and importantly, the value of an owner occupied home.

The dollar amounts for the income disregards and the asset limits are defined in nominal dollars. The income disregards have been unchanged since the program's inception and asset limits unchanged since 1989. (The initial asset limits were $\$ 1,500$ and $\$ 2,250$, were these amounts increased to 2012 dollars, the amounts would be $\$ 7,000$ and $\$ 10,500$.) Because these parameters are fixed in nominal dollars, the program has become less generous over time with fewer individuals qualifying for benefits. Given this programmatic decline in the resources one can hold and still qualify for benefits, one might then imagine that the fraction of the eligible population that actually enrolls in the program would increase as those eligible for benefits are drawn increasingly from the lowest point of the income and asset distributions. Similarly, knowledge about the program may have increased since its inception affecting take-up rates. ${ }^{3}$ Finally, attitudes toward welfare may have also changed as this period saw the advent of welfare reform, as well as enormous swings in the value of stocks and housing assets In addition to the federal program, states have the option to supplement benefits by providing higher guarantees. In 2011, 44 states and the District of Columbia offered optional

\footnotetext{
${ }^{3}$ Alternatively, one could speculate that knowledge about the program and thus participation would decline over time if the 1974 launch were associated with an outreach campaign and public relations efforts that have since faded.
} 
supplemental programs of some sort—-some benefitting all groups of eligible individuals and others limited to certain classes of individuals, such as those needing special care. State income guarantees vary greatly. For example, in 2011 California provides guarantees of $\$ 845$ for single elderly individuals and \$1,407 for couples - a supplement of approximately 40 percent for couples.

The number of elderly individuals receiving SSI benefits increased sharply in the first years of the program as knowledge about the program spread, but declined soon thereafter as Social Security benefits and coverage increased and fewer individuals were eligible for SSI benefits (Trout and Mattson, 1984). Should the real value of Social Security benefits fall in the future, one would well expect a concomitant increase in the number of elderly enrolling in SSI. This increase would mean additional federal spending through the SSI program and, if states maintain their guarantees, this increase in eligibility would affect state coffers as well. The increases in expenditures would be along two dimensions: More individuals will be eligible for benefits and benefits would be larger. However, because of the historically low rates of participation, assessing what increases in eligibility mean for enrollments, and forecasting any sort of fiscal burden of Social Security cuts on SSI, requires a model of participation. Similarly if we are to ensure participation among those who need assistance, we first need to understand the factors affecting participation.

\section{Data}

Past work has demonstrated that the amount of the benefit to which an individual is entitled is a strong predictor of whether they enroll, with those entitled to larger benefits having a significantly greater probability of participating in the program. The first step in our analysis is thus to construct a sample of elderly individuals who are apparently eligible for SSI benefits. To 
do so we need detailed income and asset data that include not just the total amount, but the components as well—particularly earnings, SSI receipt, earned versus unearned income, and housing wealth, automobile wealth, and other bequeathable wealth for a relatively large sample of older Americans. ${ }^{4}$ Ideally we would like to repeat the analysis for several years to assess whether there are any notable changes over time in response to changes in economic conditions or other macro-level factors. We therefore draw on the Health and Retirement Study - a biennial panel survey of older individuals that is approximately nationally representative of the population ages 51 or older. The first cohort of HRS respondents was interviewed in 1992 when they were approximately 51 to 61 years old - too young to qualify for SSI benefits as an elderly individual — and the second cohort in 1993 when they were age 70 or older. ${ }^{5}$ To obtain a representative sample of those 65 or older, we begin with data in 1998, when the initial cohort was older and additional cohorts were added to the HRS sample to round out the age distribution. ${ }^{6}$ We use all survey years from 1998 to $2008 .^{7}$

Because income guarantees can rise above the federal guarantees in some states, eligibility depends on the state in which the individual lives. However, if we wish to consider the possibility that an individual can relocate, perhaps to be closer to children or grandchildren, for better weather, or a lower cost of living, the choice set is less obvious. Our analysis therefore begins with a focus on eligibility at the federal level, and then extends it to include income guarantees specific to the individual's current state of residence. ${ }^{8}$ Only a small proportion of beneficiaries receive income from state programs and not from the federal program, so our

\footnotetext{
${ }^{4} \mathrm{We}$ also need information on living arrangements as SSI benefits may differ if one is living with others. ${ }^{5}$ Because spouses are interviewed, regardless of age, there will be some data on those who are age-eligible.

${ }^{6}$ In 1998 a sample of individuals born between 1942 and 1947, and a sample of those born between 1924 and 1930 were added to the survey.

${ }^{7}$ Although we have done a great deal of work with the 2012 data, we do not use these data here as we are concerned about data quality.

${ }^{8}$ We also note that access to the state identifiers is restricted, so the analysis at the federal level may be more useful for comparison to others beginning such a project.
} 
estimates of the eligible population are relatively unaffected. If anything, our estimate of the participation rate is upwardly biased by excluding from the eligible population those who are entitled to only small amounts from the state supplemental programs. In December 2010, there were 1,098,752 elderly recipients of federal SSI benefits and just 85,101 with only state benefits (SSA, 2012). In each case we examine only participation among the elderly, ignoring those entitled to benefits at younger ages due to disability.

We calculate eligibility as the Social Security Administration itself would, including all necessary income exclusions, adjusting for an ineligible spouse or for living in the household of another, when necessary. We also impose the asset test, again taking into account the exclusion of a home and a car valued at less than $\$ 4,500 .{ }^{9}$ All those with a non-zero expected benefits and with assets below the relevant maximum ( $\$ 2,000$ for a single person and $\$ 3,000$ for a couple) are considered eligible for benefits.

Despite our attention to detail and the rich information on income and assets available in the HRS, our determination of eligibility is unlikely to be perfect. In addition to the typical errors in the reporting of income, there could be additional noise introduced in our income measures because of the structure of questions in the HRS. In the survey, questions regarding the amounts stemming from various sources of income may refer to the flow of funds over different time periods. Respondents must therefore do mental calculations to answer correctly, or alternatively, may fail to recognize that the time periods vary and continually report for the same interval regardless of what the question states. With respect to income from employment, respondents are asked to report earnings during the last calendar year. In contrast, for many of the types of

\footnotetext{
${ }^{9} \mathrm{Up}$ to $\$ 4,500$ of value for a car needed for work or for transportation to medical appointments is excluded from assets. We assume all those 65 or older can justify the need for a car along one of these lines. Burial plots, household furnishing, and tools needed for employment are also excluded. The HRS does not collect this information and we make no adjustments along these lines. We have also ignored the exclusion for life insurance policies valued at less than $\$ 1,500$.
} 
income that are typically received monthly (such as Social Security and SSI), respondents are asked to report the amount received in the last month. For income from assets, such as rental property or other business income, the window of time is left to the respondent. Finally, even with error-free reporting, we could err in determining eligibility because of the varying time periods. For example, we could incorrectly mark as ineligible, someone who had high earnings in the past year, but who now has retired and has little, if any, in the way of earnings and is eligible for (or even receiving) SSI benefits. However, because the incomes of the elderly are likely to be less variable than those of the working-age population, we do not expect this issue to be of substantial importance, but we do acknowledge the potential for both type I and type II errors. In fact, among those we determine to be ineligible for benefits, slightly less than two percent report the receipt of SSI. As noted above, there are a number of reasons for this. First of all, they could be eligible for state benefits, which are excluded here; they could have misreported the receipt of SSI or of another source of income; or the time frame of the income reporting period could affect eligibility. Finally, they could simply be receiving SSI incorrectly. ${ }^{10}$

Among those whom we determine to qualify for SSI based on income, 24 percent have assets above the allowable limits. Conversely, among those who have sufficiently low assets, 78 percent are not income eligible. This asymmetry is not surprising given the exclusion of a home and car from the measure of assets and the notorious low savings rate among those in the lower portion of the income distribution (Munnell et al., 2014). ${ }^{11}$ Many in our sample have little savings other than a home.

We undertake our analysis for the survey years 1998 to 2008. Here we report participation rates for single years and use the full stacked data for seven survey years for our

\footnotetext{
${ }^{10}$ In future revisions we will include state benefits, eliminating the first source of error. We will also compare reported income across waves as a check on misreporting.

${ }^{11}$ Alternatively if one were to annuitize fully, the value of non-housing (and non-vehicle) assets would be small.
} 
regressions. As noted, we report SSI eligibility and determination based solely on the federal program. A small fraction of elderly are entitled to state benefits only and many will have slightly greater benefits were we to include the state supplements.

\section{Analysis}

One of the more surprising aspects of the program is the relatively low rate of participation. Over the entire sample period, a weighted 57.5 percent of the sample of eligible households is receiving SSI benefits. This number agrees well with those of past studies, but is a tiny bit higher given that state benefits are not included. Because those who are entitled to state benefits, but not federal benefits, will be eligible for smaller amounts, on average, and because benefit amounts have been shown to be positively related to participation, we would expect the omitted individuals to have lower participation rates and to bring down the average were they included.

Table 1 illustrates participation rates by year. We report the fraction of the entire sample that appears to be eligible for benefits and the fraction of those who are eligible who are receiving SSI income. The year 2010 stands out as an obvious outlier. We are not sure why, but note that if we exclude those who have imputed values for income, the participation rate for 2010 increases from 38 to 48 percent. The anomaly calls for further investigation, but here we simply delete observations for 2010, leaving us with a sample participation rate of 57.5 percent referenced above rather than 54.5. ${ }^{12}$

Table 2 illustrates the differences in observable characteristics between the population as a whole and those who appear to be eligible for SSI benefits. We divide this latter group of eligibles into those who are not receiving SSI and those who do report the receipt of benefits. By

\footnotetext{
${ }^{12}$ We note also that the correlation between reported SSI income and calculated federal benefits in 2010 is just 0.19 while it is approximately 0.5 in other years.
} 
definition, those who are eligible for benefits are worse off financially with lower income and assets, but the differences are dramatic. For example, average nonhousing wealth for the full sample is $\$ 316,000$, compared to less than $\$ 100$ for the eligible groups. Home ownership and car ownership also show dramatic differences. Seventy-seven percent of the sample owns a car compared to 25 and 36 percent for the two samples of eligibles. Note that car or home ownership is a measure of wealth, but could also depend on health. If those in the eligible group are in worse health (and they are), they may not be able to use a car or maintain a home.

In addition to the financial measures, there are also large differences in education levels with the population average being approximately 12 years of schooling and those receiving SSI having fewer than eight years on average. This difference suggests that this group was disadvantaged early on and old-age poverty may simply reflect a lifetime of low income. The probability of being nonwhite is nearly three times higher among the eligible groups than for the population as a whole. Although there are some age differences, they are smaller than might be imagined, but there are large differences in the probability of being married; 40 percent of our full sample is married compared to just 12.8 percent of participants and 15.9 percent of nonparticipants. This result is consistent with the extremely high poverty rate for elderly widows and the loss in both income and wealth following the death of a spouse (McGarry and Schoeni, 2005).

While these differences between the eligible and ineligible populations are not surprising, what might be surprising are the large differences between participants and nonparticipants. Even though both groups fare poorly relative to the population of the United States, those who are receiving benefits are substantially worse off than those who do not. The calculated benefit for participants is nearly $\$ 100$ per month higher, they are more likely to be nonwhite and have less schooling. In terms of income, it is particularly interesting to note the relatively low rate of 
Social Security receipt among the eligibles. Just 73 percent of those receiving SSI benefits also report the receipt of Social Security benefits.

One of the potential factors that has been ignored in previous studies is the potential role of the family. To that end, we focus in Table 3 on the relationship between characteristics of the children and participation. Consistent with the strong SES gradient across the three groups, eligible units have more children with participating units having the greatest number. Socioeconomic differences do not appear to have vanished (or even diminished much) by the next generation. The average education of the children of those receiving SSI benefits is just 11.75 years compared to 14 years for those ineligible for benefits and 12.4 for those eligible nonparticipants. Similarly, average income of the children varies along the same lines: Nearly $\$ 60,000$ for the children of ineligible individuals, $\$ 29,000$ for participants, and $\$ 35,600$ for children of eligible nonparticipants. ${ }^{13}$

While we would expect family transfers to augment or substitute for SSI income, the low SES of the children of those who are eligible for benefits suggests that they may lack the capacity to support their parents. While their capacity is certainly limited, we do see a strong correlation between participation and financial assistance from children. Among those who are not eligible for benefits, 5.3 percent received a financial transfer from at least one child. This rate of receipt is similar to the 5.6 percent for eligible participants. However, among the eligible nonparticipants, the likelihood of receiving a transfer is approximately twice as high at 11.1 percent. Despite the substantially lower income of the children of these respondents, many are giving to parents. The difference in the conditional amounts between participants and nonparticipants is also great. With eligible nonparticipants not only being twice as likely to receive assistance, but

\footnotetext{
${ }^{13}$ Income of children is reported in categories. Here we use the midpoint of the category. Future work will impute a value based on the CPS / ACS.
} 
conditional on receiving something, on average they receive more than twice as much, $\$ 6,614$ compared to $\$ 2,630$. Although it is not possible to infer causality, this result is consistent with family support crowding out public assistance. Those who are receiving SSI do not appear to have family who are able to transfer, while many of those who do not collect benefits are benefiting from transfers.

In order to assess the importance of SSI and family support, Table 4 examines the components of income for these three groups. The differences in total incomes are dramatic, as was seen in Table 2. Those who are ineligible for SSI benefits receive substantial income from earnings, pensions, and capital income while the eligible groups receive almost nothing from these sources. Even annual Social Security is low for the two groups of eligible individuals. The SSI participants do, however, report the receipt of substantial Social Security disability benefits of nearly $\$ 4,000$ per year. ${ }^{14}$ Of most interest are the numbers in the bottom panel. As is apparent, the transfers from children for the eligible nonparticipants nearly offset the nonreceipt of SSI benefits for those lucky enough to receive family assistance.

\section{Multivariate analysis}

While some of the eligible nonparticipants are obviously benefiting from

family support, others appear to be getting by with little assistance of any type. To understand better the decision to enroll in SSI, we turn to a regression analysis and examine the multivariate correlations. We limit the sample to those who appear to be eligible for SSI benefits and use as our left-hand side variable an indicator of whether they report receiving income from SSI. Our explanatory variables are chosen to proxy the costs and benefits of participation that have been hypothesized by previous authors. Obviously the greater the expected benefit, the more likely

\footnotetext{
${ }^{14}$ Individuals who are first entitled to Social Security as disabled individuals are reclassified as retirees at the normal retirement age, but we suspect that many continue to view their Social Security benefits by their initial classification.
} 
individuals ought to be to enroll as the benefit from participation is more likely to outweigh any associated costs. We also include assets because the marginal utility of additional income ought to be more valuable for those with little other resources, so the benefit gained from enrolling is less in utility terms and potentially more likely to be outweighed by any associated costs. These measures are on a household basis, so a married couple with the same income or assets as single person are worse off financially, and the marginal utility of SSI income (and thus participation) ought to be higher. Because SSI recipients in most states are categorically eligible for Medicaid, we include poor health as a measure of the value of this additional health insurance. Medicaid, and thus the participation in SSI which confers eligibility, is more valuable for those who have greater health care needs.

Many of the explanations for nonparticipation center on the lack of knowledge about the program or the inability to deal with the administrative burden of applying for benefits. Perhaps the most widely cited "cost" is that of the potential stigma associated with receiving welfare. Such a cost was first formalized in Moffitt (1983). We use proxies for each of these costs.

As proxies for knowledge, we include schooling level (of the male in a couple), a measure of cognitive ability (average for a couple), and because one of the primary ways of informing individuals about their potentially eligibility is through the Social Security system, we also include an indicator of whether the individual / couple is receiving Social Security benefits. Finally, given the link between SSI receipt and eligibility for Medicaid, many individuals enroll in SSI through their contact with the medical system. For that reason we include an indicator of whether the individual or spouse had a hospitalization at any prior point during the survey.

Availability of a car, age, health, and cognition will help control for the difficulty of the application procedure itself, which may involve getting to a Social Security office and filling out 
required forms. Race, rural residence, and region of the country have previously been posited to be related to the stigma of welfare receipt and we will include them here.

Finally, we include measures of potential family support. We experimented with including the number of children, number of daughters, number of children living within 10 miles, and an indicator of whether the respondent has any children. Certainly the ability of children to provide financial support could affect enrollment in the program, so we include a measure of the income of the children in the family. While it is difficult to know how to measure the ability of children to provide support, we have chosen to proxy the potential for such support by including the income of the child with the greatest income among all siblings. Although this need not be the most generous child, or the child most able to help, it is in some sense the income of the child whom we would expect to have the most disposable income. We also include average education of the children.

The results for these regressions are reported in Table 5. These results are preliminary and subject to change as we both refine our measures of the right-hand side variables and include benefits from state programs. The magnitude of the expected benefit is strongly positively related to enrollment. Age, too, is a significant predictor, but is negatively related to enrollment. Surprisingly, there is no significant difference by rate, but schooling and marital status do have significant predictive power with those who are married or with high levels of schooling being less likely to enroll. Surprisingly, owning a home and not the value of countable assets (nonhousing assets) is negatively related to participation.

Despite the strong results in the descriptive tables, differences across children do not appear to affect participation in a multivariate context. 


\section{Conclusion}

The Social Security program has done much to improve the well-being of the elderly and the sharply falling poverty rates for the elderly throughout the 1960s and 1970s attest to its importance. However, changes to Social Security are likely, including likely reductions in benefits. For those elderly with low incomes, there does exist an important safety net in the form of the SSI program. However, many of those eligible for SSI are not enrolled in the program. This study has begun to attempt to understand the barriers to enrollment, and in doing so, provide some guidance as to how better to reach low-income elderly in the future, and how the federal and state governments might expect enrollments in SSI to change with changes in Social Security.

We focus specifically on the role of family and find evidence to suggest that those elderly with higher-income children are less likely to enroll in the program, as are those who are receiving a transfer from a child. 


\section{Bibliography}

McGarry, Kathleen, "Factors Determining Participation of the Elderly in SSI," 1996, The Journal of Human Resources, 30 : s268-s292.

McGarry, Kathleen, "Guaranteed Income: SSI and the Well-being of the Elderly Poor," 2002, in The Distributional Effects of Social Security and Social Security Reform, Martin Feldstein and Jeffrey Liebman, eds. Chicago: University of Chicago Press : 49-79.

McGarry, Kathleen, 2014. "The Social Safety Net for the Elderly, 2014. Forthcoming in The Legacy for War on Poverty: Implications for the Future of Anti-Poverty Policies, Martha Bailey and Sheldon Danziger, New York: Russell Sage.

McGarry, Kathleen, and Robert Schoeni, 2005. "Widow Poverty and Out of Pocket Medical Expenses Near End of Life,” The Journals of Gerontology: Social Sciences, 60B (3) : s160-s169.

Menefee, John, Bea Edwards, and Sylvester Schieber, 1981. "Analysis of Nonparticipation in the SSI Program," Social Security Bulletin, 44 (6) : 3-21.

Moffitt, Robert, 1983. “An Economic Model of Welfare Stigma,” The American Economic Review, 73 (5) : 1023-1035.

Munnell, Alicia, Matthew Rutledge, and Anthony Webb, 2014. "Are Retirees Falling Short? Reconciling the Conflicting Evidence." Paper presented at the 2014 Investment Company Institute Retirement Summit. Washington DC April 4, 2014.

Social Security Administration, 2012. Social Security Bulletin Annual Statistical Supplement, 2011. February B-164031(4); HRD-76-176. December 6.

Staats, Elmer, Comptroller General of the United States, 1976. Efforts Made to Locate and Enroll Potential Recipients of the Supplemental Security Income Program for the Aged, Bland, and Disabled. B-164031(4); HRD-76-176. December 6.

Trout, John and David Mattson, 1984. "A 10-Year Review of the Supplemental Security Income Program," Social Security Bulletin, 47 (1) : 3-24.

Warlick, Jennifer, 1982. "Participation of the Aged in SSI," The Journal of Human Resources 17(2) 236260. 
Table 1

Participation Rates by Survey Year

(based on Federal program only)

\begin{tabular}{|l|l|l|}
\hline & Percent Eligible Receiving SSI & Number Eligible \\
\hline 1998 & 57.7 & 603 \\
\hline 2000 & 58.5 & 595 \\
\hline 2002 & 55.2 & 519 \\
\hline 2004 & 61.9 & 473 \\
\hline 2006 & 56.0 & 546 \\
\hline 2008 & 55.7 & 503 \\
\hline 2010 & 37.6 & 446 \\
\hline Total & 57.5 & 3239 \\
Total with 2010 included & $(54.7)$ & $(3685)$ \\
\hline
\end{tabular}




\begin{tabular}{|c|c|c|c|c|c|c|}
\hline \multicolumn{7}{|c|}{$\begin{array}{c}\text { Table } 2 \\
\text { Sample Means and Standard Errors }\end{array}$} \\
\hline & & & & & ible & \\
\hline & \multicolumn{2}{|c|}{ All } & \multicolumn{2}{|c|}{ Participants } & \multicolumn{2}{|c|}{ Nonparticipants } \\
\hline Variable & Mean & Std Err & Mean & Std Err & Mean & Std Err \\
\hline Calculated benefit & 17.5 & $(4.958)$ & 292.55 & $(5.35)$ & 195.9 & $(5.14)$ \\
\hline Age (avg for couples) & 74.98 & $(0.036)$ & 75.5 & $(0.189)$ & 76.1 & $(0.21)$ \\
\hline Nonwhite & 0.12 & $(0.002)$ & 0.416 & $(0.012)$ & 0.375 & $(0.012)$ \\
\hline Schooling (avg) & 11.90 & $(0.015)$ & 7.19 & $(0.099)$ & 8.58 & $(0.101)$ \\
\hline Married & 0.41 & $(0.002)$ & 0.128 & $(0.008)$ & 0.159 & $(0.009)$ \\
\hline Own home & 0.75 & $(0.002)$ & 0.35 & $(0.012)$ & 0.542 & $(0.013)$ \\
\hline Receive Soc Sec & 0.962 & $(0.001)$ & 0.731 & $(0.011)$ & 0.878 & $(0.008)$ \\
\hline Receive earnings & 0.209 & $(0.002)$ & 0.012 & $(0.003)$ & 0.057 & $(0.006)$ \\
\hline Amount of earnings & 581.78 & $(10.88)$ & 4.47 & $(1.84)$ & 31.30 & $(4.36)$ \\
\hline Car & 0.768 & $(0.002)$ & 0.246 & $(0.011)$ & 0.356 & $(0.013)$ \\
\hline Live with others & 0.255 & $(0.002)$ & 0.384 & $(0.012)$ & 0.364 & $(0.012)$ \\
\hline Poor health & 0.389 & $(0.002)$ & 0.691 & $(0.011)$ & 0.573 & $(0.013)$ \\
\hline Non housing assets & 316,486 & $(58,627)$ & 67.28 & $(229)$ & 3.70 & $(95.3)$ \\
\hline Cognitive score & 21.56 & $(0.027)$ & 16.6 & $(0.167)$ & 16.73 & $(0.183)$ \\
\hline Number of obs & \multicolumn{2}{|c|}{40,988} & \multicolumn{2}{|c|}{1716} & \multicolumn{2}{|c|}{1523} \\
\hline & & & & & & \\
\hline
\end{tabular}




\begin{tabular}{|c|c|c|c|c|c|c|}
\hline \multicolumn{7}{|c|}{$\begin{array}{c}\text { Table } 3 \\
\text { Sample Means and Standard Errors Child Characteristics }\end{array}$} \\
\hline & \multicolumn{2}{|c|}{ Ineligible } & \multicolumn{4}{|c|}{\begin{tabular}{|c|} 
Eligible \\
\end{tabular}} \\
\hline & & & \multicolumn{2}{|c|}{ Participants } & \multicolumn{2}{|c|}{ Nonparticipants } \\
\hline Variable & Mean & Std Err & Mean & Std Err & Mean & Std Err \\
\hline \multicolumn{7}{|l|}{ Numbers: } \\
\hline Number of children & 3.15 & $(0.017)$ & 4.05 & $(0.084)$ & 3.76 & $(0.074)$ \\
\hline Any children & 0.915 & $(0.001)$ & 0.848 & $(0.009)$ & 0.894 & $(0.008)$ \\
\hline Number of daughters & 1.60 & $(0.007)$ & 2.21 & $(0.053)$ & 1.85 & $(0.044)$ \\
\hline Number coresident & 0.225 & $(0.003)$ & 0.373 & $(0.018)$ & 0.390 & $(0.018)$ \\
\hline Number live nearby & 1.037 & $(0.006)$ & 1.51 & $(0.047)$ & 1.31 & $(0.046)$ \\
\hline \multicolumn{7}{|l|}{ SES } \\
\hline Average education & 14.0 & $(0.020)$ & 11.75 & $(0.112)$ & 12.41 & $(0.126)$ \\
\hline Average income & 59,500 & $(186)$ & 29,650 & $(933)$ & 35,600 & $(1090)$ \\
\hline Fraction own home & 0.554 & $(0.002)$ & 0.364 & $(0.060)$ & 0.40 & $(0.011)$ \\
\hline Age of oldest child & 51.2 & $(0.044)$ & 53.8 & $(0.237)$ & 53.6 & $(0.266)$ \\
\hline \multicolumn{7}{|l|}{ Transfers to Parent } \\
\hline At least one transfer & 0.053 & $(0.001)$ & 0.056 & $(0.006)$ & 0.110 & $(0.008)$ \\
\hline Conditional Amount & 5491 & $(228)$ & 2630 & $(288)$ & 6614 & $(909)$ \\
\hline Expect help in the future & 0.484 & $(002)$ & 0.300 & $(0.011)$ & 0.387 & $(0.013)$ \\
\hline Number of obs & & 0988 & & 716 & & 23 \\
\hline
\end{tabular}




\begin{tabular}{|c|c|c|c|c|c|c|}
\hline \multicolumn{7}{|c|}{$\begin{array}{c}\text { Table } 4 \\
\begin{array}{l}\text { Sample Means and Standard Errors Income Components } \\
\text { (Values are measured on an annual basis) }\end{array}\end{array}$} \\
\hline & \multicolumn{2}{|c|}{ Ineligible } & \multicolumn{4}{|c|}{ Eligible } \\
\hline & & & \multicolumn{2}{|c|}{ Participants } & \multicolumn{2}{|c|}{ Nonparticipants } \\
\hline Variable & Mean & Std Err & Mean & Std Err & Mean & Std Err \\
\hline Total Income & 51,518 & $\begin{array}{l}(2003) \\
\end{array}$ & 8832 & $(77.7)$ & 6581.60 & $(91.5)$ \\
\hline \multicolumn{7}{|l|}{ Components: } \\
\hline Earnings & 7,370 & $(139.2)$ & 53.6 & $(22.1)$ & 375.6 & $(52.3)$ \\
\hline Pension & 12,899 & $(1960)$ & 42.8 & $(10.2)$ & 125.5 & $(18.9)$ \\
\hline Social Security & 15,623 & $(40.0)$ & 4231 & $(75.9)$ & 5709 & $(79.7)$ \\
\hline SS Disability & 186.8 & $(7.3)$ & 3985 & $(75.2)$ & 68.7 & $(18.2)$ \\
\hline $\mathrm{UI} / \mathrm{WC}$ & 49.6 & $(3.7)$ & 1.6 & $(1.5)$ & 3.7 & $(2.0)$ \\
\hline Capital income & 12,747 & (244) & 14.8 & $(4.4)$ & 33.7 & $(4.8)$ \\
\hline Other govt income & 30.6 & $(1.6)$ & 495.7 & $(26.7)$ & 260.1 & $(20.4)$ \\
\hline Other & 2,614 & $(264)$ & 7.8 & $(3.3)$ & 5.0 & $(2.2)$ \\
\hline Transfer from child $(0 / 1)$ & 292 & (14) & 141 & $(22)$ & 703 & $(111)$ \\
\hline Conditional Amount & 5491 & $(228)$ & 2630 & $(288)$ & 6614 & $(909)$ \\
\hline Unconditional Amount & 292 & (14) & 142 & $(22)$ & 703 & (111) \\
\hline SSI & 65 & $(3.1)$ & 3841 & $(71.6)$ & 0.0 & 0.0 \\
\hline Totals & \multicolumn{2}{|c|}{$\frac{1}{40,988}$} & \multicolumn{2}{|c|}{1523} & \multicolumn{2}{|c|}{$\frac{1}{1716}$} \\
\hline
\end{tabular}




\begin{tabular}{|c|c|c|c|c|}
\hline \multirow[b]{3}{*}{ Variable } & \multicolumn{4}{|c|}{$\begin{array}{c}\text { Table } 5 \\
\text { Linear Probability Model of Participation }\end{array}$} \\
\hline & \multicolumn{2}{|c|}{ (1) } & \multicolumn{2}{|c|}{$(2)$} \\
\hline & Coeff & Std Err & Coeff & Std Err \\
\hline Calculated benefit (100's) & 0.036 & $(0.008)$ & 0.033 & $(0.009)$ \\
\hline Age (avg for couples) & -0.007 & $(0.002)$ & -0.006 & $(0.002)$ \\
\hline Nonwhite & 0.033 & $(0.028)$ & 0.022 & $(0.034)$ \\
\hline Schooling (avg) & -0.021 & $(0.004)$ & -0.016 & $(0.005)$ \\
\hline Married & -0.114 & $(0.037)$ & -0.119 & $(0.044)$ \\
\hline Own home & -0.122 & $(0.023)$ & -0.129 & $(0.033)$ \\
\hline Receive Soc Sec & 0.023 & $(0.044)$ & 0.036 & $(0.053)$ \\
\hline Receive earnings & -0.342 & $(0.056)$ & -0.333 & $(0065)$ \\
\hline Poor health & $(0.057)$ & $(0.026)$ & 0.092 & $(0.033)$ \\
\hline Assets $(10,000 \mathrm{~s})$ & 0.021 & $(0.014)$ & 0.022 & $(0.033)$ \\
\hline Cognitive score & 0.004 & $(0.002)$ & 0.005 & $(0.003)$ \\
\hline Number of children & & & 0.009 & $(0.007)$ \\
\hline Number live nearby & & & 0.018 & $(0.049)$ \\
\hline Received $\$$ from kids & & & -0.075 & $(0.053)$ \\
\hline Number of obs & \multicolumn{4}{|c|}{2208} \\
\hline Mean of dep var & \multicolumn{4}{|c|}{0.55} \\
\hline R2 & \multicolumn{2}{|c|}{0.11} & \multicolumn{2}{|c|}{0.125} \\
\hline
\end{tabular}

